https://doi.org/10.1007/s11061-016-9497-1

"This is a post-peer-review, pre-copyedit version of an article published in Neophilologus. The final authenticated version is available online at: http://dx.doi.org/10.1007/s11061-016-9497-1".

\title{
Un "instante antimaquiavélico" de Quevedo en Inglaterra: Christian Politicks contra tiranos ateos, discípulos de Satanás
}

\author{
María José Alonso Veloso \\ Universidad de Santiago de Compostela
}

Quevedo cerraba el capítulo octavo de uno de sus más tempranos tratados, Discurso de las privanzas -según todos los indicios, anterior a España defendida (1609)-, con la promesa de dedicar toda su vida a la refutación de Maquiavelo.

Con estos preceptos un privado no temerá ni será temido; asegurará de sí y asegurarase de otros, y todos en unos mesmos medios, sin usar de los que el Maquiavelo disculpa con decir que los dice por malos, sabiendo que saben todos que es refrán y modo de decir antiguo: "no digo", y decirlo. No le impugno aquí más, porque pienso ocupar parte de mi vida en escribir contra todas sus obras (p. 148)

Esta declaración de intenciones de Quevedo se acompañaba de nuevas referencias antimaquiavélicas explícitas, en el título del capítulo siguiente, donde "refuta una opinión de Maquiavelo" (p. 149) sobre si el privado debe ser temido o amado. Su propósito declarado apenas oculta la faceta de Quevedo como "tratadista de corte realista, poco alejado de Maquiavelo pese a declaraciones en sentido contrario", como desvela Rey (2012, p. 74). De hecho, llega a reconocer "acertado" (p. 157) el parecer de Maquiavelo sobre la necesaria crueldad en los castigos.

Su reflexión política se adscribía así desde el inicio de su trayectoria literaria al género del tratado antimaquiavélico, inaugurado por Botero y secundado en España por autores como Rivadeneira, quien había subrayado la necesidad de combinar acción política y virtud, en una obra de 1595 (Rey 2012, pp-20-26). Con su título inequívoco “Tratado [...] contra lo que Nicolás Maquiavelo y los políticos de este tiempo

\footnotetext{
${ }^{1}$ La expresión es un guiño a la acuñada por Pocock (1975), “The Machiavellian Moment”, previamente enunciada por Skinner. Sobre el concepto remito a las aclaraciones de García (2002, pp. 23-26) en el estudio preliminar de la traducción española y el propio Pocock en su introducción (2002, pp. 77-80). Este artículo es resultado de proyectos del Ministerio de Economía y Competitividad (RYC-2012-10138) y la Xunta de Galicia (EM2014/007).
} 
enseñan"-, apuntaba contra postulados medulares de $I l$ principe de Maquiavelo, difundido en 1531 y objeto de controversia en la historia del pensamiento político europeo, al calor de su coincidencia temporal con el protestantismo y la Contrarreforma (Rey 2013, p. 21). De su impacto son muestra elocuente los numerosos escritos sobre la "razón de estado" difundidos en Italia, Inglaterra, Francia, Alemania y España durante los siglos XVI y XVII, y aun con posterioridad (Fernández-Santamaría 1986; Cantarino 1996). Y también la sintética caracterización literaria acuñada por Gracián en Criticón: "Éste es un falso político llamado el Maquiavelo"; sus mentirosos aforismos son "una confitada inmundicia de vicios y de pecados. Razones, no de estado, sino de establo [...] con que tiene embelesados a tantos y tontos" (crisis séptima, pp. 165-166). No en vano, como subrayaba García (2002 p. 13):

la reinterpretación de Maquiavelo y de su pensamiento es algo que vienen proponiendo sin cesar desde hace casi quinientos años, los Pablo Paruta, Saavedra Fajardo, tacitistas, Quevedo, Francis Bacon, Rousseau, Federico II de Prusia, Fichte, Nietszche, Gramsci, Croce, Meinecke.

La figura del escritor florentino está presente en los tres tratados políticos mayores de Quevedo: además del ya citado, Política de Dios y Marco Bruto, de fecha más tardía. La condena de Maquiavelo acompañó a Quevedo hasta el final de sus días, pero hoy se sugiere que no llegó a ser capaz de "dar a Maquiavelo la réplica definitiva a la que aspiraba" (Rey 2013, p. 30), porque constató la imposibilidad de ajustar la política a la ética, pero también por su creciente escepticismo vital. La alternativa al pensamiento maquiavélico buscada en Política de Dios "desembocó en la duda sobre el poder y en la sospecha de que no era posible ajustarlo a un patrón moral” (Rey 2013, p. 28). Aceptando tal fracaso parcial en sus pretensiones, parece claro que la insistencia de Quevedo en su objetivo podría explicar la rápida asimilación de su pensamiento político en el contexto europeo, interpretado como adalid de la causa antimaquiavélica, a veces previamente adaptado o manipulado. Así se entiende la extraordinaria fortuna de una obra como Política de Dios, y la apropiación que de la misma se hace en Inglaterra en los primeros años del siglo XVIII, ${ }^{2}$ cuando se altera de modo significativo su título para amoldarlo a las particulares circunstancias políticas y religiosas del país en aquel contexto histórico. Si en 1715 la versión inglesa de la primera parte se insertó en la

\footnotetext{
${ }^{2}$ Decía Clamurro (1991, pp. 121 y 153) que la primera parte "was something of a best-seller when it was first published in 1626", por número de ediciones y traducciones; y que "the notable popularity and official approval of the work when it appeared suggest that the Politica found important resonance in the mentality and political vision of the age" (p. 153). Fernández-Guerra (1946, p. 5) aseveraba que "la que cuenta más de treinta ediciones debe de llevar el sello de un mérito indisputable".
} 
literatura política panfletaria que canalizó la polémica entre los partidos whig y tory, ${ }^{3}$ cinco años más tarde la segunda parte se concibió como dardo contra "la locura de tiranos maquiavélicos y estadistas ateos".

Este artículo analiza la traducción inglesa de la segunda parte de Política de Dios, publicada en 1720 sin mención de su traductor ni textos preliminares que la justifiquen, tomando en consideración el contexto en que se inserta. Tal propósito requiere una rápida síntesis inicial de tres aspectos que juzgo de interés para entender los rasgos de la traducción: la difusión de los textos políticos de Quevedo en Europa, con especial atención al territorio inglés; la recepción de Maquiavelo en Inglaterra hasta el siglo XVIII; y la presencia del florentino en la obra quevediana. Aunque no pretenden ser más que tenues pinceladas de los temas esbozados, iluminan un poco la explícita e intensa lectura antimaquiavélica que el anónimo traductor inglés pergeñó cuando recuperó el tratado político, y el propio estudio de la traducción que se propone.

\section{La literatura de Quevedo en Europa: obras políticas en Inglaterra}

La preferencia de los lectores de Francia, Italia, Inglaterra o Alemania por la obra burlesca de Quevedo es bien conocida: lo evidencian las ediciones y reediciones múltiples del Buscón y los Sueños. ${ }^{4}$ Pero lo destacado de tal vertiente ha parecido velar el impacto de otras esferas de la literatura de Quevedo, no tan masivo, pero tal vez más significativo por su apego a círculos intelectuales de prestigio. ${ }^{5}$ Entre tales facetas destaca la difusión de su pensamiento político en Europa, en los siglos XVII y XVIII, a través de traducciones de sus tratados a distintas lenguas europeas, pero también de ciertas obras de narrativa lucianesca, o satírico-morales, de contenido y propósito políticos evidentes: Discurso de todos los diablos o La Fortuna con seso y la hora de todos. Su éxito evidencia un interés paralelo al suscitado por textos políticos de Guevara, Furió Ceriol, Rivadeneira, Saavedra Fajardo o Gracián.

\footnotetext{
${ }^{3}$ La traducción, de autoría desconocida, se titula Divine maxims of Government without Whig or Tory. Or the true character of a King and of a tyrant, of a faithful minister and of a favourite traitor. Véase el análisis de Alonso Veloso (2016). Decía Clamurro (1991, pp. 4 y 20) que "Quevedo was by inclination something of a pamphleteer and perhaps even a libelista" y "Some texts [...] are emphatically propagandistic and can be seen as products of Quevedo's sometime role as a pamphleteer".

${ }^{4}$ Los Sueños y el Buscón se vertieron al italiano, el francés, el inglés, el alemán y el holandés. Sobre versiones italianas, Garzelli (2011) y Nider (2011, 2012 y 2013), acerca de los Sueños y Marco Bruto y la Carta a Antonio de Mendoza, respectivamente; Martinengo y Símini (2003) sobre el Buscón. Acerca de las francesas, Roig Miranda (1997, 2000 y 2011). Algunas traducciones inglesas fueron estudiadas por Arbesú (2006), Barker (1945) y Navarro (1987). Ehrlicher (2011) se ocupó de la difusión alemana.

${ }^{5}$ No deben olvidarse traducciones de ciertos textos morales, como las versiones italianas de Doctrina moral (Alonso Veloso, 2013), en 1684, y Carta a Antonio de Mendoza (Nider 2012 y 2013), en 1738; o La cuna y la sepultura en holandés (Ámsterdam), en 1730.
} 
Marco Bruto impulsó cinco traducciones en cuatro idiomas diferentes: italiano (Venecia, 1653), latín (La Haya, 1660; Ámsterdam, 1669), holandés (Ámsterdam, 1700) e inglés (Londres, 1710). ${ }^{6}$ De Política de Dios se conocen dos impresiones con una traducción italiana publicadas a comienzos del XVIII (Mantua, 1701 y Venecia, 1709); ${ }^{7}$ una temprana edición polaca (Varsovia, 1645) ${ }^{8}$ dos inglesas tardías (Londres, $1715 \mathrm{y}$ 1720); y también una francesa, conservada en un manuscrito del siglo XVII, que traduce al francés íntegramente la primera parte y ha sido localizado recientemente. ${ }^{9}$ A ellas debe sumarse la versión italiana de Carta a Luis XIII (1636). ${ }^{10}$ Pero también Discurso de todos los diablos se tradujo en Francia e Inglaterra, lugar este último donde se elaboró la versión inglesa de otra obra lucianesca, La Fortuna con seso y la Hora de todos (Fortune in her Wits, or the Hour of All Man, 1697). Como se aprecia, en Inglaterra germinó un particular interés por la literatura política quevediana, que alcanzó a títulos variados, consecutivos en el breve lapso comprendido entre los años finales del siglo XVII y las primeras décadas del XVIII. Discurso de todos los diablos, La Fortuna con seso y la hora de todos, Primera parte de la vida de Marco Bruto y Política de Dios (las dos partes) ${ }^{11}$ configuraron un catálogo quevediano alternativo a su obra burlesca más conocida (Sueños y Buscón), defendido ya por John Stevens en su traducción de La Fortuna con seso, en $1697 .{ }^{12}$ El afamado capitán y traductor ${ }^{13}$ expresaba su aprecio por las creaciones en prosa quevedianas, en un manuscrito en forma de catálogo de libros españoles del siglo XVII (Williams 1936; Scott 1904, p. 505), donde manifestaba haber traducido Política de Dios, y ponderaba su erudición y piedad religiosa. ${ }^{14}$

\footnotetext{
${ }^{6}$ Véase el estudio de Alonso Veloso (2015a) sobre las traducciones de esta obra.

${ }^{7}$ Una tercera, publicada en Trento, por Antonio Brunati, carece de fecha; véase Crosby (1966, p. 593). Crosby dice sobre la procedencia del texto de la primera: "sin identificar" (p. 591). Acerca de la traducción de la segunda parte, los ocho capítulos iniciales (pp. 3-75), indica que su fuente fue "una de las ediciones de la segunda parte de la Política, a partir del año 1655" (p. 592).

${ }^{8}$ Remito a Eminowicz (1984) y Kwiatkowska Farys (2002).

${ }^{9}$ Se titula La politique de Dieu, le gouvernement de Jesus Christ et la tirannie de Satan y ha sido descrita por Alonso Veloso (en prensa); puede leerse una breve información sobre el hallazgo en el siguiente enlace: http://mariajosealonso.wix.com/transmision-quevedo\#!novedades/c10pu. Sobre las traducciones de Política de Dios, Fernández-Guerra (1946, p. CX), Astrana (1943, p. 1439; 1946, p. 773) y Crosby (1966, pp. 588-593). Sobre la polaca, Eminowicz (1984) y Kwiatkowska Farys (2002).

${ }^{10}$ Puede consultarse el análisis de Barone (2014).

${ }^{11}$ Sobre los principios que operan en la traducción y modificación de textos traducidos, consúltese Burke (2010, pp. 24-25); sus apreciaciones son pertinentes para la segunda parte de Política de Dios.

${ }^{12}$ Véase el "Preface" de la princeps de su traducción, Fortune in her Wits, or the Hour of all Men.

${ }^{13}$ Además de obras de Quevedo (Comical Works o Fortune in her Wits), tradujo muchos textos literarios españoles del Siglo de Oro y revisó la versión inglesa del Quijote a cargo de Shelton.

${ }^{14}$ Decía: Divine Politicks in two Parts [...] both full of Piety \& Learning \& show him well / read in Divinity, as well as Humanity; but if they have any Fault, it is their / Length \& perhaps the overstraining of Texts of Scripture. I have translated both / Parts, but none is yet printed (Williams 1936, p. 150).
} 
El atractivo de la fortuna de Quevedo en Inglaterra reside no sólo en la inusitada preferencia por su literatura política, sino en los propios rasgos de las traducciones, en particular sus largos títulos, el elemento más alejado del original. Transformados para dotar a la obra de un significado más preciso desde la propia portada, con la ayuda de otras manipulaciones ideológicas, modelan las versiones inglesas a la medida de la realidad política inglesa del momento. Y ello a pesar de que en muchos casos siguen los textos españoles y no ciertas traducciones intermedias, particularmente las francesas, ${ }^{15}$ usual punto de partida para otros tipos de obras traducidas.

\section{Maquiavelo en Inglaterra}

La fortuna del ideario de Maquiavelo en Inglaterra, peculiar pero conectada con la influencia ejercida en el conjunto del escenario europeo, resulta favorecida por el éxito de la reforma protestante, que obliga a legitimar la libertad religiosa y anima a separar política y religión, pero también por el clima de corrupción política que afecta al Estado, en un camino hacia la restauración emprendido al menos en parte a través de las ideas de Maquiavelo. ${ }^{16}$ En la transición entre los siglos XVII y XVIII, ${ }^{17}$ Inglaterra se encuentra inmersa en un clima de corrupción en el gobierno; y Europa encuentra en la doctrina del florentino, entre otras, una forma de legitimación para su prodigiosa transformación en todos los órdenes. El pensamiento occidental moderno, y el inglés en particular, recibe una clara influencia de Maquiavelo, como demostró Pocock (1975), quien acuñó la expresión "momento maquiavélico" para referirse a la crisis que atraviesa Inglaterra en distintos órdenes de su actividad en el tránsito entre los dos siglos. A propósito del viejo continente, la "crisis de la conciencia europea" plasmada por Hazard (1988), especialmente en las dos décadas comprendidas entre 1689 y 1710.

Existen multitud de estudios sobre la influencia de Maquiavelo en Inglaterra durante las dinastías sucesivas de los Tudor (1485-1603) y los Estuardo (1603-1714), ${ }^{18}$

\footnotetext{
${ }^{15}$ Acerca de la procedencia y los tipos de traducciones, remito a Burke (2010, p. 32) y Baldwin (2010).

${ }^{16}$ Sobre Maquiavelo en la cultura anglo-americana hasta el siglo XX, véase Arienzo y Borrelli (2009).

${ }^{17}$ Puede consultarse la síntesis de Woodward (1993) y Várnagy (2000) acerca de este momento histórico.

${ }^{18}$ De modo muy sintético y atendiendo a los principales hitos políticos de este amplio período, cabe recordar que, después de la dinastía de los Tudor, se instauró la de los Estuardo: el intento de aumentar su poder y limitar el del parlamento por parte de los primeros, Jaime I y Carlos I, generó un conflicto político, salpicado también por luchas de carácter religioso, que desembocó en la guerra civil de 1642 y la ejecución del segundo en 1649, abriéndose así el período denominado "Interregnum", de 11 años de duración, en el que Inglaterra no tuvo rey y destacó el papel del general Oliver Cromwell, una etapa que finalizó con el regreso del exilio de Carlos II, coronado en 1660; la Revolución Gloriosa de 1688, que depuso a Jaime II (sustituido por María y Guillermo III), tuvo como consecuencia la ulterior dependencia
} 
que demuestran que el maquiavelismo fue elemento crucial para la cultura política inglesa del XVII y el XVIII, así como su importancia en el republicanismo antes y después de la Revolución de 1642. ${ }^{19}$ Expresiones como "maquiavelismo" y "razón de estado" fueron reflejo de la necesidad de acercarse a la política y al arte de gobernar desde supuestos seculares. Al principio del XVII, el impacto del florentino fue apreciable en el escenario conflictivo del debate sobre el papel de la política y la religión: considerado la imagen más oscura de la política, Maquiavelo se presenta como cínico, tiránico y satánico en el bando antimaquiavélico, en la medida en que habría favorecido una ruptura del equilibrio tradicional entre religión y política, y así su figura fue utilizada tanto por el bando católico como por el reformista. Esta vertiente tan negativa no impidió que su análisis de la política y razón de estado llegase a situarle entre los tratadistas políticos fundadores de la política moderna, en un proceso que conduce desde el rechazo de sus obras hasta su aceptación, al menos implícita. La expresión "razón de estado", traducida con términos diferentes ("state necessity", "laws of state", "mystery of state"...) en una trayectoria peculiar dentro del contexto europeo, cobra auge al principio del XVII en Inglaterra, coincidiendo con los llamados conflictos “constitucionales" e inserta en el amplio debate sobre el alcance de la prerrogativa real.

En el proceso de configuración de la monarquía parlamentaria inglesa, a finales del XVII, la figura de Maquiavelo representa un amplio referente conceptual, que permite abordar el papel limitado de la religión en la política, el modelo republicano entre las formas de gobierno mixto, la adaptación de las formas de gobierno a los nuevos tiempos, o la plasmación institucional de una soberanía política que abre el camino para la monarquía constitucional inglesa y la republic estadounidense.

Pero conviene apuntar algunos hitos en la apropiación del pensamiento político del florentino, hasta las décadas iniciales del siglo XVIII, cuando la obra de Quevedo se traduce con un acusado sesgo antimaquiavélico. En 1539, décadas antes de que los tratados contrarreformistas difundidos al final del siglo XVI y el principio del XVII condenaran la "razón de estado" de Maquiavelo, el cardenal Reginald Pole describía sus ideas como emanadas del diablo: "malitiam Satanae redolent", "Satanae digito", afirmaba en Apologia ad Carolum Quintum (citado por Khan 1994, p. 87). En dicha

de los monarcas del parlamento en el ejercicio del poder. A partir de 1714 se instauró la nueva dinastía de los Hannover, que, con Jorge I y Jorge II, coincide con la llamada época de la "supremacía whig".

${ }^{19}$ Con distintos enfoques, propósitos y conclusiones, cito sólo algunos de los más relevantes, sin ánimo de profundización ni exhaustividad: Mosse (1950), Raab (1964), Pocock (1975), Skinner (1998), Burgess (1992) o Meinecke (1997), entre otros. 
obra acusaba a Thomas Cromwell de leer y aprobar Il principe, "Satan's Bible", de estar "possessed of an army of devils" y ser "an emissary of Satan to the King" (Dycke 1904, p. 708). ${ }^{20}$ Se inicia aquí una larga y compleja cadena de recepción del florentino en Inglaterra, entre cuyos eslabones cabe citar a Gardiner, Bacon, ${ }^{21}$ Raleigh, Shakespeare o Marlowe, ${ }^{22}$ en sucesión incesante y polémica, que combina la condena airada con el reconocimiento implícito de la relevancia que sus teorías adquieren en circunstancias contemporáneas marcadas por una crisis de autoridad política y religiosa. Si bien sus doctrinas recibieron duros ataques por el uso de medios y fines inmorales, consideradas "secret teaching whose poison was spreading through Christendom" (Donaldson 1988, p. 2), y su figura fue metafórica "personificazione del male” (Procacci, p. 221), lo cierto es que la llamada "razón de estado" se tornó en práctica tolerable, tanto para católicos como para protestantes, convenientemente justificada por razones de fe, avalada por intenciones religiosas.

Tras la guerra civil y la proclamación del parlamento como encarnación legítima de la soberanía, adquirió fuerza una visión de Maquiavelo como teórico republicano, ya no sólo como aquel instructor de príncipes ateo y cínico. El "humanismo cívico" o el "republicanismo clásico", originado en la particular experiencia de la república florentina entre los siglos XV y XVII, cobró especial vigencia en el siglo XVII inglés, sobre todo a través de Harrington, quien lo popularizó y propuso como solución para los problemas políticos que afrontaba Inglaterra en la década de 1650 (Ríos Espinosa 2011, pp. 145-147). Concebida como diferenciada de la liberal, la tradición del pensamiento republicano -que hunde sus raíces en Cicerón y la antigua Roma- habría sido continuada por Maquiavelo en el Renacimiento italiano, por James Harrington y otros autores durante la guerra civil de Inglaterra en el XVII, así como por numerosos teóricos de Inglaterra, Francia y Norteamérica ya en el XVIII (Abellán 2001). A Harrington, "profundo conocedor del pensamiento maquiavélico", habría correspondido el papel de “dar un nuevo sesgo el discurso republicano" y la "reformulación de su paradigma", que desembocó en una profunda controversia y en el triunfo definitivo del "patrón de pensamiento de la modernidad en la reorganización de la comunidad política" (García 2002 pp. 25-26), practicada por la monarquía británica en aquel siglo.

\footnotetext{
${ }^{20}$ El trabajo de Dycke evidencia que, si bien Cromwell no puede ser considerado un mártir, su condición de "diabolically inspired disciple of Machiavelli" (p. 724) es producto de la imaginación de Pole.

${ }^{21}$ Véase Peltonen (1992), a propósito del acercamiento humanístico a la política que promueve en sus ensayos, donde combina diversas fuentes además de Maquiavelo: Tácito, Lipsio o Montaigne, entre otros. ${ }^{22}$ El teatro isabelino contribuyó mucho a popularizar la obra de Maquiavelo (Procacci 1995, p. 220).
} 
En su análisis de la historia del "momento maquiavélico" en el pensamiento inglés y americano de los siglos XVII y XVIII, Pocock (2002, p. 79) busca demostrar que la tradición política inglesa "estaba informada por los conceptos y valores republicanos y maquiavélicos, tanto como por los constitucionalistas de Locke y Burke”. En tal contexto, la obra de Harrington, particularmente La república de Oceana (1656) publicada en un período no monárquico, en el que sus ideas republicanas influyeron en el partido whig- adquiere un valor central, como síntesis del humanismo cívico, la conciencia político-social inglesa y la teoría maquiavélica. Maquiavelismo y humanismo se convierten en instrumento contra "el primer capitalismo moderno" (p. 80). De ahí que Pocock plantee la pregunta paradójica de "cómo fue posible que las formulaciones del republicanismo de Maquiavelo y Harrington pudieron parecer apropiadas en la monarquía parlamentaria de la Inglaterra de la Restauración” (p. 489), en referencia al proceso entre 1675 y 1680, marcado por la publicación de panfletos relacionados con la interpretación neoharringtoniana de la política inglesa.

Otras figuras capitales en la historia del pensamiento político inglés han sido relacionadas con la recepción de Maquiavelo, estudiada entre otros por Raab (1964). En un contexto de guerras civiles en Inglaterra, entre 1640 y 1660, derivadas de la lucha entre el Parlamento y la Corona por la soberanía, se inscribe por ejemplo la obra de Hobbes (1588-1679), quien opta por la monarquía absoluta en Leviatán (1651) y alerta de la extensión del republicanismo entre sus contemporáneos; interpretadas como una enfermedad, las teorías de Maquiavelo habrían "infectado" antes de la Restauración a Milton, Marvell, Sydney, Neville o Harrington, entre otros. Y cabe citar también la filosofía política de Locke (1632-1704), padre del individualismo liberal, enfrentado a las tendencias deudoras de Maquiavelo. ${ }^{23}$

Pocock (2002) traza las líneas básicas de la historia del debate suscitado ante la ruptura de las monarquías absolutas -acerca de alternativas a la concepción unilateral de la política contractualista, con el monopolio del gobierno concentrado en los representantes elegidos por los ciudadanos-, desembocando en el siglo XVIII, en torno a la figura destacada del estadista y escritor Bolingbroke (1678-1751). Esta etapa histórica marca en su opinión el momento culminante de la recepción del florentino en el ámbito inglés: “el período histórico en que la reputación de Maquiavelo como cabeza

\footnotetext{
${ }^{23}$ O Bernard Mandeville (1670-1733): "Maquiavelo liberó a la política de la Iglesia, mientras que Mandeville liberó al deseo humano de su moralización” (Ríos Espinosa 2011, p. 156).
} 
visible del moralista cívico alcanzó mayor reconocimiento, lo que permitió que permanecieran ocultas las referencias a su ambigüedad moral” (p. 584).

En el contexto citado, precedido por la fama de sus escritos burlescos y encuadrado en la corriente de pensamiento que opone la falsa razón de estado del florentino frente a la verdadera razón de estado, cristiana, la obra política de Quevedo pudo añadirse sin dificultad a la causa antimaquiavélica, tal vez necesitada de argumentos para combatir la remozada figura del florentino, estadista republicano y fino historiador político. No en vano su negativa imagen, antimaquiavélica, seguía viva en la multitud de panfletos que, lanzados contra los monarcas y los parlamentos, producen la ilusión de compartir propósito con una Política de Dios concebida para otro contexto.

\section{Quevedo frente a Maquiavelo}

Clamurro (1991, p. 121) ya advirtió del peligro de interpretar la obra de Quevedo como un mero tratado contra Maquiavelo, olvidando su faceta de "exhortación moral" al monarca: "The Politica might at first seem simply a political tract in the antiMachiavellian tradition”. Le habían precedido Lira (1948, p. 200), quien señalaba que para Quevedo "la razón de Estado [...] viene a constituir el obstáculo principal [...] contra la realización del bien común social [...] se erige así en el enemigo irreconciliable de Maquiavelo y de toda la política renacentista"; o Lida (1968-69, p. 201), que consideraba que con Política de Dios "le es fácil a Quevedo incluirse en la prestigiosa serie de tratadistas para quienes Maquiavelo es el adversario por excelencia”. También sobre dicho tratado, Hernández (1999) proponía una síntesis explícita de su propósito ya desde el título: "Quevedo contra Maquiavelo". Partiendo de estudios clásicos como los de Fernández-Santamaría, Maravall o Ruiz de la Cuesta, Marañón (2005, p. 49) abogaba por matizar la idea del eticismo y la postura contraria a la razón de estado de Quevedo, evidente en Política de Dios, pero no así en obras anteriores y posteriores, donde se percibe "una clara influencia maquiavélica". Abarcando la totalidad de sus tratados políticos, Rey (2012, pp. 32-33) sugería que, para contrarrestar al florentino, "se aferró a la virtud estoica y la doctrina del bien común para encaminar al príncipe por la senda recta", subrayando algunos puntos de contacto entre ambos, alejados del proclamado propósito quevediano (pp. 34-37). En referencia a la época de escritura del Discurso de las privanzas, advertía que "sus discrepancias con Maquiavelo eran escasas, pese a las manifestaciones en sentido contrario" (p. 37). Tal proceder vacilante, condenando explícitamente a Maquiavelo pero usándolo entre líneas para su 
argumentación, atañe también a otros textos de Quevedo, como Lince de Italia, que Rey (2015, p. XXVII) califica como "escrito técnicamente maquiavélico". ${ }^{24}$ Y su estrategia recuerda la de autores ingleses como Walter Raleigh, quien apunta hacia el florentino "en términos reprobatorios" en The Maxims of State, pese a escribir en esencia un libro “maquiavélico" (Pocock 2002, p. 432). En síntesis, “en el siglo XVII se le combate e insulta, pero en el fondo todos los políticos lo siguen" (Formoso 1973, p. 61).

Si nos atenemos a las declaraciones explícitas o las alusiones directas, Discurso de las privanzas es la obra que contiene un mayor número de denuestos contra Maquiavelo, lo que no obsta para que los argumentos de Quevedo se deslicen muchas veces hacia el pensamiento de aquél: responsable de escribir "cosas con que se perdió y se pierden muchos que le siguen, digo todos" (p. 145); malinterpretar los textos sagrados, "a que se arrima para auctorizar su error y maldad", con un intento "falso" para prolongar "la monarquía de un tirano" (p. 146); y no reparar "en conciencia" (p. 146) cuando está en juego la hacienda. En diversos lugares contradice las consignas del florentino: "contra Maquiavelo", prueba lo desaconsejable de que reyes o privados escandalicen o provoquen temor en el pueblo; rechazando los medios por él propuestos, le quita la máscara para evitar que se usen "los que el Maquiavelo disculpa con decir que los dice por malos, sabiendo que saben todos que es refrán y modo de decir antiguo: "no digo", y decirlo" (p. 148), antes de anunciar que consagrará su vida a combatirlo; denunciando "un error del Maquiavelo [...] en El príncipe" y "su disparate" sin disculpa (p. 150), defiende que el rey sea temido y severo, pero nunca cruel.

La mención directa e insultante cede el paso a la alusión en la segunda parte de Política de Dios, cuyo antimaquiavelismo, reconocido por sus contemporáneos y la crítica, resulta más evidente en el capítulo sexto. En él, Pilato, "grande político, afectaba la disimulación y la incredulidad, que son los dos ojos del ateísmo” (p. 385), y fue “eminentísimo como execrable estadista" (p. 389), en referencia a las teorías de Maquiavelo, de manera particular su "sinrazón de estado": "Halaga con la primera promesa de conservar y adquirir, empero ella — que llamándose razón de estado es sinrazón - tiene siempre anegados en lágrimas los designios de la ambición. Su proprio nombre es "conductor de errores, máscara de impiedades"” (p. 388). Y a propósito de la pérfida disimulación o hipocresía, que no duda en calificar como "grande virtud

\footnotetext{
${ }^{24}$ Sobre la presencia de Maquiavelo en la obra de Quevedo, véase Rey (2013); Ghia (1994, pp. 107-146) y Díaz Martínez (2000, pp. 93-105) también abordaron su ambigua postura ante el italiano. Hernández (1999, pp. 700-707) analizó su presencia en Política de Dios.
} 
política" en Marco Bruto (p. 827), aunque "pecado moral", su invectiva atañe a los “pomposos discípulos de Tácito y del impío moderno”, en obvia alusión a Maquiavelo: ambos "beben en estos arroyuelos el veneno de los manantiales de Pilato" (p. 389).

La pretendida "templanza y razón de Estado" también se esgrime para denostar las maniobras ocultas de quienes difunden libelos por "puertas y cantones" (p. 792) en Marco Bruto; o para denunciar una justicia subordinada a la razón de estado incluso en una obrita burlesca, Papel de las cosas corrientes en la Corte, donde ondean "banderas por la razón de estado sobre las almenas de la justicia” (p. 370). La figura arrojadiza del florentino sirve asimismo para destapar los intentos detestables contra la Corona española en política exterior, en el memorial de inspiración maquiavélica Lince de Italia, donde se lee que "El duque de Saboya ha tomado por sí la exhortación lisonjera que Nicolás Maquiavelo hace al fin del libro del tirano que él llama príncipe” (p. 55).

En la sátira lucianesca no faltan personajes de clara impronta maquiavélica en sus razonamientos, siempre inmersos no obstante en la ambigüedad característica del género: en Discurso de todos los diablos, Juliano, que parece aceptar "la inmoralidad como forma de gobierno" (Rey 2003, p. 540, nota 373), en la tradición maquiavélica, cuando aconseja a los escritores de "políticas y advertimientos" escribir no "lo que había de ser [...] no lo que debía ser [...] sino lo que puede ser y es posible" (p. 540). Pero también el monarca francés de La Fortuna con seso, quien, bajo la aparencia de "buen católico", exhibe su condición de "astuto político", hipócrita y "Jano de la religión, que con una cara mira al turco y con otra al Papa" (p. 763). O, en la misma obra, la probable alusión a la política maquiavélica de Olivares (Schwartz 2003, pp. 784-785, nota 1070), en boca de Pacas Mazo, quien muestra un libro encuadernado en pellejo de oveja cuyo autor es "Nicolás Maquiavelo, que escribió el canto llano de nuestro contrapunto" (p. 784).

Incluso los tratados religiosos, teñidos de reflexión política en tantas de sus páginas, acumulan consideraciones sobre la razón de estado, siempre vinculada a figuras execrables como los judíos asesinos de Jesucristo, en La caída para levantarse, o Luzbel, "el ángel comunero", en Providencia de Dios, donde el serafín caído "luego que perdió la honra, inventó el duelo; luego que perdió el estado de la gracia, inventó la materia de estado. Con ésta destruyó el mundo, pues por materia de estado y ser como Dios pecaron los primeros padres" (p. 1405).

El sesgo antimaquiavélico adjudicado a la obra de Quevedo y los pasajes señalados, entre otros que podríamos aducir, bastarían para explicar que en Inglaterra 
sus escritos políticos se hubiesen utilizado como interesada arma de papel al comienzo del siglo XVIII, después de décadas convulsas en lo político y lo religioso, asimiladas y naturalizadas ya las teorías de Maquiavelo, cuando el país abrazaba oficialmente ya el anglicanismo y sentaba las bases de su monarquía parlamentaria, no sin grandes tensiones entre facciones y partidos. La fama indiscutible del autor español, célebre en el escenario europeo por sus textos burlescos y conocido en los más reducidos círculos intelectuales y humanísticos por sus tratados graves, pudo hacer el resto.

\section{Christian Politicks contra tiranos maquiavélicos}

La traducción al inglés de la segunda parte de Política de Dios contiene sólo los 8 primeros capítulos de los 23 que comprende el original, publicado de forma póstuma por Pedro Coello en 1655. De esta forma, conserva la parte del texto de Quevedo que más explícitamente apunta contra las ideas de Maquiavelo, en su asimilación a la figura de Pilato, localizada en el capítulo sexto. A diferencia de la princeps, a la que parece seguir en su estructura y contenido, carece de cualquier texto preliminar, legal o literario, y empieza de modo abrupto con el primer capítulo. Resulta llamativo que la traducción inglesa contenga sólo ocho capítulos, precisamente el mismo número que la versión variante de la obra, más breve, conservada en un manuscrito de la Real Academia de la Historia; pero no puede haber partido de él, debido a que el orden y el contenido de los capítulos son muy diferentes. ${ }^{25}$

Siguiendo una práctica que ya ha sido descrita en el caso de la traducción de la primera parte (Alonso Veloso 2016), la obra de 1720 prescinde de las citas latinas, generalmente bíblicas, y mantiene sólo su versión inglesa, que sigue en todos los casos la correspondiente glosa de Quevedo en español. Este criterio, que parece un intento de adaptarse a un lector habituado ya en Inglaterra a oficios religiosos desarrollados en lengua vulgar exclusivamente, ${ }^{26}$ se acompaña de una sistemática adición de referencias bibliográficas a pie de página, que precisan o complementan información más breve o ausente en el original: acotaciones del tipo "I Sam. XVI 22, 23", "Matt XVII 4", "Phil. II. 6”, “John VI, 54, 55, 56”, "Psal. LIII. 4”, "Luke VII 20, 21, 22”, “Prov. XXI. 1.” o "Ibid v 15" van aportando la exacta localización de una cita, a veces poco precisa, como

\footnotetext{
${ }^{25}$ Crosby (1959, p. 77) estudió el manuscrito, con signatura Ms 9/5134 Rh, y explicó la redistribución de los capítulos respecto a la princeps de1655, que reorganiza, corrige y amplía el otro texto.

${ }^{26}$ El Prayer Book y los textos bíblicos, pero también la liturgia, usaban el inglés, y cada vez menos lectores o fieles podían entender latín; sobre este asunto, véase Rosman (1996, pp. 10-11, 18 y 27).
} 
cuando la indicación "Matthaei 26; Lucae 22" (378) se sustituye por "Matt XXVI 67. Luke XXII 63" (38).

También sobre las referencias bíblicas, se constata idéntico afán de fidelidad a la fuente sagrada cada vez que el traductor modifica la cita glosada por Quevedo: ampliándola, recortándola, ajustándola al texto de las Sagradas Escrituras, o precisando el origen con expresiones como "and the Evangelist adds" (64) o "the Text says" (66).

Mayor testimonio tengo que Juan Bautista, porque las obras que hago dan testimonio de mí (375); But I have greater witnesses than that of John; for the works which the Father hath given me to finish, the same works that I do, bear witness of me (36)

De la casa deste perverso le llevaron atado a la de Caifás, donde el príncipe de los sacerdotes y todo el concilio solicitaban hallar un falso testimonio contra Jesús para entregarle a la muerte, y no le hallaron, con haber venido muchos testigos falsos (379); Now the chief priest and elders, and all the council, sought false witnesses against Jesus to put him to death, but found none; yea, tho' many witnesses came (40-41)

En el segundo ejemplo existe una modificación de la cita, con omisión de la primera parte, tal vez porque el texto de Quevedo no es cita literal de un pasaje bíblico, sino amalgama y paráfrasis de varios: Mateo 26, 57 y 59-60; Marcos 14, 53 y 55-56 y Juan 18, 24. La versión inglesa parece seguir más de cerca Mateo 26, 59-60.

Dejando de lado la significativa abreviación del tratado de Quevedo, que carece de los múltiples preliminares y los 15 capítulos finales (pp. 409-606), la intervención más destacada consiste en la completa alteración del título, en una estrategia de manipulación ideológica que alcanza al conjunto de la obra y su interpretación. Mientras el original opta por la escueta reiteración de los dos sintagmas coordinados que habían prosperado en la tradición textual de la primera parte, "Política de Dios y gobierno de Cristo" - pues Quevedo eliminó “tiranía de Satanás” ante las críticas recibidas $^{27}$-, la traducción inglesa altera y amplifica el título, conservando apenas la inexacta expresión inicial "Christian politicks", pero transformando el libro en una explícita denuncia de la locura de "tiranos maquiavélicos y estadistas ateos", cuyo objetivo es lograr la "conversión o confusión" de tales "hombres mundanos", que aprenden "sus máximas infames en la escuela de Satán": Christian politicks, in opposition to the folly of Matchavellian tyrants, and atheistical statesmen; for the conversion or confusion of those worldly great men, who learn their infamous maxims in the school of Satan. Así reformulado, el título en la versión inglesa apunta al epígrafe del capítulo sexto de la obra original: "La materia de estado fue el mayor enemigo de Cristo. Dícese quién la inventó y para qué” (p. 383), contenido en el que parece haberse

\footnotetext{
${ }^{27}$ Más información sobre los detractores y su impacto, en Alonso Veloso (2015b, pp. 124-126).
} 
inspirado la adición "in opposition to the folly of Matchavellian tyrants". La portada aun incluye una mención de la fuente, Quevedo, magnificada con una referencia a su éxito en Inglaterra: "Author of the celebrated Visions of Hell, etc.".

La lectura antimaquiavélica que propicia el nuevo título acuñado en la versión inglesa va acompañada de otras alteraciones que parecen obedecer a razones políticas. La de más relieve atañe a la expresión "materia de estado", evocadora de la teoría del florentino. Existe algún caso en que se mantiene y traduce -"la materia de estado y el duelo" (386); "State Policy and the Law of Duel" (48)-, pero el traductor prefiere la omisión, tal vez suponiendo que la incorporación de conceptos maquiavélicos, incluso para refutarlos, podría atenuar la invectiva buscada desde el título:

Tercera vez tentó por materia de estado con la torre de Babel escalar el cielo y hacer vecindad con las piedras y ladrillos a las estrellas, y que sus almenas fuesen tropiezo a los caminos del sol. Creció en grande estatura su frenesí hasta que la confusión la puso límite (387); His third Attempt was to climb Heaven by means of the Tower of Babel; this Madness ran to a great Height, "till the Confusion of Tongues put a stop to it (49)

Halaga con la primera promesa de conservar y adquirir, empero ella — que llamándose razón de estado es sinrazón - tiene siempre anegados en lágrimas los designios de la ambición. Su proprio nombre es "conductor de errores, máscara de impiedades" (388); om. (50)

Si en el primer caso elimina el concepto, además de simplificar el pasaje, en el otro opta por suprimir íntegramente la explícita mención de la "razón de estado" y las referencias a las teorías de Maquiavelo en torno a los medios para la "conservación y adquisición" del principado. Que Quevedo hubiese destruido jocosamente el sintagma, convirtiéndolo en "sinrazón de estado", no debió de parecer suficiente: mejor ni siquiera mentarlo. $^{28}$

En sentido contrario pero coherente con el antimaquiavelismo declarado del título, el traductor prefirió explicitar algo la velada alusión a Maquiavelo, el "impío moderno" en Política de Dios, tal vez suponiendo que la identificación del sujeto denostado podía resultar oscura o ambigua:

¿Quién negará de los que son pomposos discípulos de Tácito y del impío moderno que no beben en estos arroyuelos el veneno de los manantiales de Pilato? (389); Which of the stately Disciples of Tacitus, or of the more wicked modern Machiavel can deny, but that he sraws his poisonous Doctrine from this Practice of Pontius Pilate? (51)

Se aprecia asimismo un intento de proponer una equivalencia entre el ministro y el diablo no existente en el original: frente al individuo malvado concreto al que apunta Quevedo cuando señala "no permitiendo que el ministro diablo" (402), el traductor lee

\footnotetext{
${ }^{28}$ Aunque la omisión le obliga a precisar "have made State Policy" (50) en la referencia siguiente "la han hecho" (388).
} 
"to prevent the Minister, that is a Devil" (68), sugiriendo que el ministro es siempre un demonio.

Razones políticas y religiosas combinadas parecen subyacer a la eliminación de un pasaje en el que Quevedo halaga al monarca español, exculpándolo a él y a sus ministros de las prácticas culpables que denuncia:

con vuestra majestad, señor, nadie lo hace porque todos los que os sirven os reverencian, os aman y os temen. Vos, señor, ni lo hacéis ni lo haréis, porque es vuestra majestad católico, piadoso, vigilante y muy justificado monarca (395); om. (58)

Como en la traducción de la primera parte de Política de Dios, cercana a la que analizamos en su deliberada adaptación al contexto inglés de las primeras décadas del siglo XVIII y en la ocultación del nombre del traductor, existen leves alteraciones del original que parecen impuestas por la diferente realidad cultural y religiosa inglesa. ${ }^{29}$ Muy llamativa resulta la sistemática omisión del nombre y las palabras de Pedro Crisólogo. Venerado por los católicos y doctor de la Iglesia por iniciativa del papa Benedicto XIII en 1729, de su exclusión parece deducirse el afán de conectar con una sensibilidad anglicana y apartarse de la Iglesia Católica Romana.

siguiendo esta doctrina, san Pedro Crisólogo (Serm. CIV, del rico que tenía fértil heredad) examinando el soliloquio interno de su avaricia en aquella pregunta: "Quid faciam? ¿Qué haré?”, dice: “¿con quién hablaba éste? alguno otro tenía dentro de sí, porque el demonio que le poseía se había penetrado en sus entrañas. el que se entró en el corazón de Judas poseía lo retirado de su mente. Mas oigamos qué le responde el consejero interior: "destruiré mis trojes". Evidentemente se descubrió el que se escondía, porque siempre el enemigo empieza por destruir" (358-359); To torment and destroy does not belong to Christ (19)

(en quien, como dice san Pedro Crisólogo, Sermón 174: "los pasos quebrados, el cuerpo disoluto, desencuadernada la compage de los miembros, las entrañas derretidas con el artificio" valieron por textos y leyes contra la cabeza sacrosanta de el más que profeta) (396); om. (58)

La supresión general de la devoción a los santos, asociada con el rechazo de las imágenes sagradas, explica también la siguiente alteración de la versión inglesa:

(acción realísima, ponderada por tal de los santos), dijo Cristo: "Zelus domus tuae comedit me. el celo de tu casa me come", que son del verso 10 del Salmo 68, todo misterioso de la pasión del señor (369); saying, The zeal of thine house hath eaten me up (28)

Si la mención de los santos resultaba siempre censurada, lo mismo sucede con expresiones que el lector podía situar de modo automático en una esfera católica de la que Inglaterra estaba ya oficialmente apartada desde el reinado de Enrique VIII: figuras como la del Papa, monarcas de fervoroso catolicismo, creencias auspiciadas por la Iglesia romana como su fundación por san Pedro... Los cambios delatan el esmero del

${ }^{29}$ Sobre la convulsa historia inglesa en materia política y religiosa durante los siglos XVI y XVII, pueden consultarse Clark (1977), Woodward (1993), Briggs (1994), Questier (1996), Rosman (1996), Maltby (1998), Scott (2000) o Varela (2000), entre otros. 
traductor por evitar expresiones sospechosas de apartarse del anglicanismo o simpatizar con la doctrina católica:

Vuestra majestad le atienda con la católica piedad de su alma (360); your Majesty, as a true Christian, may reflect upon it (20)

Testifícalo en la transfiguración san Pedro cuando, de piedra fundamental de edificio eterno, se metió a maestro de obras y le dijo (362); This plainly appears in S. Peter at the Transfiguration, when he said (22)

¿Quién será, señor, el católico que quiera (367-368); What Christian will desire (27)

después que instituyendo el santísimo sacramento del altar (368-369); Afterwards, as the Institution of the holy Eucharist (28)

y le comieron los suyos [referido al sacramento] (369); om. (28)

Sacra, católica, real majestad (374); Great Sir (35)

Existe una sistemática sustitución del término "católico" por "cristiano" y una eliminación del concepto de "sacramento" referido a la Eucaristía. Luteranos y anglicanos, pese a conservar la misa, eliminaron partes consideradas no conformes con la interpretación de las Sagradas Escrituras: la alusión a los méritos, la invocación a María y los santos o la idea de la misa como sacrificio. La polémica transubstanciación, que enfrentaba a la ortodoxia católica con el protestantismo, fue negada en todas las iglesias reformadas (Rosman 1996: 31), aunque se aceptaba la presencia del Señor resucitado en la comunidad celebrante y la unión con él: siguiendo el principio "extra usum nullum sacramentum", se piensa que Cristo está presente entre los fieles que celebran y no en los elementos, lo que en la práctica implicó la pérdida de la costumbre de conservar la hostia consagrada y toda forma de veneración de la misma entre protestantes y anglicanos.

Sólo se mantienen las referencias explícitas al catolicismo del monarca cuando se trata de figuras históricas inconfundibles, cuando no hay riesgo de que tal rasgo se atribuya por ejemplo al rey de Inglaterra, lo que no obsta para que se eliminen las menciones a la Iglesia de Roma, cuando existen:

sois rey grande y católico, hijo del Santo, nieto del Prudente, biznieto del Invencible (369); you are a great and Catholick King, Son to the Holy, Grandson to the Wise, and great Grandson to the Invincible (28)

La casa de Dios, señor, es su templo; su iglesia, la congregación de sus fieles, sus creyentes. Vuestra majestad es el mayor hijo de la Iglesia romana, cuanto más obediente monarca glorioso de los católicos, pueblo verdaderamente fiel (369-370); The House of God, Sir, is his Church, the Congregation of the Faithful. Your Majesty is the greatest Son of the Catholicks, a truly faithful People (29) 
En el primer caso se mantiene la referencia a Felipe III, Felipe II y Carlos V, mencionados con sus sobrenombres usuales. En el otro también, pero la histórica ruptura anglicana con la iglesia de Roma determina su omisión.

Otras alteraciones relacionadas con el diferente contexto religioso atañen, por ejemplo, al dogma central de la Trinidad sobre la naturaleza de Dios, pese a que fue aceptado en la mayoría de las iglesias cristianas.

Veamos cómo se cumplió esto. El proprio libro nos lo dice, donde el Espíritu Santo se encargó de lo más importante en estas materias (349); Let us see this verify'd in the same book (8)

la materia fue la más grave que dispuso el Padre Eterno y que obró el Espíritu Santo y que ejecutó el amor del Hijo (373); This was one of the weightiefs Works of divine Providence (34)

A la omisión simple del Espíritu Santo se añade la completa sustitución de las tres personas (Padre, Hijo y Espíritu Santo) que contendría Dios como ser único, sin que quepa justificar tal intervención en creencias particulares anglicanas.

La leve (en apariencia) sustitución de "las religiones" (367), una alusión a las órdenes religiosas, por "the religious" (27) apunta hacia la aún vigente historia de persecución del catolicismo: Enrique VIII, quien promulgó en 1534 el Acta de Supremacía por la cual declaró a la corona británica como cabeza suprema y única de la Iglesia en lugar del Papa en Inglaterra, disolvió las órdenes religiosas, que se sometieron a excepción de franciscanos y cartujanos. La alusión a ellas habría resultado conflictiva, cuando en el imaginario colectivo aún pervivía la expulsión, el apresamiento o el martirio de los franciscanos, cuyos monasterios fueron clausurados, o los mártires de la Cartuja de Londres. Las represiones religiosas consiguientes durante el siglo XVI -de orientación opuesta, bajo María I e Isabel I- se prolongaron en el XVII y el XVIII, con protestas y disturbios de signo anticatólico.

De menor calado son otras modificaciones como el cambio de "conjuros" (353) por "Prayers" (12); de "sacrosanta humanidad" (380) por un inocuo "whole humanity" (41); y la omisión de "siendo católicos" (388).

A lo largo de la traducción se constata una tendencia acusada a la abreviación, que parece obedecer a distintos propósitos de carácter estilístico. El autor de la versión inglesa evita los pasajes más metafóricos, en los que Quevedo recrea y comenta un pasaje bíblico de aplicación en las acciones de gobierno, o aquellos en los que describe con enumeraciones acumulativas y enfáticas, por ejemplo la apariencia del gobernante, más atenta a la imagen que proyecta de sí que a su verdadera esencia: 
bien puede alguno mostrar encendido su cabello en corona ardiente en diamantes, y mostrar inflamada su persona con vestidura, no sólo teñida, sino embriagada con repetidos hervores de la púrpura, y ostentar soberbio el cetro con el peso del oro (374); a Man may appear crown'd with glittering Diamonds, clad in costly Robes, holding a golden Scepter (35)

Herodías, bailando sobre el hielo de un río vengador de la maldad de sus mudanzas, rompiéndose, la sumergió y, haciendo cadahalso los carámbanos, fue degollada de los filos del hielo impetuoso. Pies que fueron cuchillo para la garganta de Juan fue justo que hiciesen del teatro de sus bailes cuchillo para la suya (396); Herodias dancing on a frozen River was drown'd, and her Head cut off by the Ice (59)

En todos los casos la eliminación de expresiones superfluas puede haberse debido no sólo a su carácter prescindible, sino a la dificultad de traducir pasajes figurados. La referencia metafórica al suicidio de Judas se sustituye por otra más directa, y aún más notable resulta la simplificación de la descripción poética sobre el final de Herodías. Del mismo tipo parece el cambio de "le pase el cuchillo por la garganta" (400) a "be the executioner" (64).

Abundan las omisiones completas de apelaciones directas al monarca: "Señor" (354, 379, 381, 384); "Suplico a vuestra majestad oiga benignamente mis razones (386); “serenísimo y soberano señor” (387-388); “muy poderoso rey y señor nuestro" (389); “¡oh, señor!” (389). O las de consideraciones ponderativas de Quevedo, que parecen buscar una reacción favorable del receptor ante sus argumentos: "en estos renglones se tocan tantas trompetas como hay palabras" (390); “¿Quién ha dicho que con manos limpias no se puede hurtar?” (390). Y también aclaraciones parentéticas, como “(tal es la palabra antigua que le dijeron)" (407).

En otros casos, el traductor juzgó innecesarias ciertas aclaraciones culturales, explicaciones etimológicas con las que el filológo Quevedo comenta alguna palabra de su fuente bíblica. Siguiendo un procedimiento habitual, la versión inglesa elimina los términos latinos "fur" y "latro" (403; 68); y omite el dilatado excurso de Quevedo sobre el término "didracma", inserto en medio del pasaje bíblico en el original $(407 ; 73)$. Otras supresiones tienen menor extensión y se concentran en enumeraciones de varios miembros. El resultado es un discurso menos enfático, pero sin cambios apreciables en el sentido general del pasaje. ${ }^{30}$

Las adiciones no son tan frecuentes, si se exceptúan las referencias bíblicas ya comentadas. Cuando se producen, tienden a deshacer la ambigüedad de una expresión

\footnotetext{
${ }^{30}$ Menciono sólo algunas de ellas: Nada les perdones ni codicies alguna de sus cosas (350), and spare them not (9); los calumnian y acusan y desacreditan (361), slander and discredit those (21); fértiles de sentidos $y$ de doctrina y ejemplo (366), they abound in doctrine and instruction (25); de la justicia que se las niega u del castigo que los corrige (383), against Justice and its Punishments (45); solamente habría hombres en las horcas, hogueras y cuchillos (401), all Mankind would soon be executed (66).
} 
concisa que remite a un referente o un hecho ya citado, aunque no faltan ciertas amplificaciones en enumeraciones, tal vez buscando mayor claridad. Salvo alguna excepción, los ejemplos evidencian que en el terreno de las adiciones el efecto de la manipulación del original español fue menor que en el de las omisiones y, de forma aun más acusada, en el de las sustituciones analizadas. ${ }^{31}$

\section{Conclusión}

La traducción de la segunda parte de Política de Dios canaliza una difusión del tratado de Quevedo en territorio inglés que altera sustancialmente el texto original, mutilado y reducido a sólo un tercio de su extensión, lo que impidió al lector acceder al desarrollo discursivo del autor, en su propuesta de un gobierno terrenal a imagen del espiritual de Cristo, basado en ejemplos mayoritarios de las Sagradas Escrituras. El característico tono sermoneador del escritor español se mitiga un tanto, además, en la medida en que Christian Politicks omite muchas de las apelaciones directas al monarca, con propósito de instrucción y enmienda. Aunque de relieve, las citadas no son las alteraciones más importantes. Las de mayor calado atañen a un deliberado amoldamiento ideológico de la fuente para subordinarla a unos propósitos e intereses que podemos calificar como políticos en primera instancia, aunque no exentos tampoco de intenciones religiosas.

Sobre estas últimas, resulta claro el alejamiento de la doctrina emanada de la Iglesia de Roma y la reescritura en clave de protestantismo anglicano: un contexto "cristiano", pero no católico; donde el culto a los santos se desvanece, y particularmente la figura de Pedro Crisólogo; donde la trinidad, la transubstanciación y las órdenes religiosas son cautelosamente veladas.

Inmersa en las transformaciones políticas que conducen a la monarquía parlamentaria, y después de dos siglos de apropiación del pensamiento de Maquiavelo, usualmente encubierta y casi siempre polémica, Inglaterra accede a una versión inglesa de la Política de Dios de Quevedo que hiperboliza su antimaquiavelismo. Tal vez la manipulación del traductor se vio favorecida por la fama del español como azote del florentino, explícitamente declarada en distintos lugares de su obra desde el inicio de su

\footnotetext{
${ }^{31}$ Entre todas las adiciones, destaco unas pocas: cuando pidieron las sillas (358), and when they ask'd, to sit on his right and left hand (18); Yo soy el prometido (374), I am the promis'd Messias (35); se heló de manera (378), grew so cold in Charity and Zeal (39); tentándole para acusar a Cristo (393), to try, or tempt him, that they might have something to charge him with (57); Y oyendo esto uno tras otro se iban, empezando los más ancianos (400), And they which heard it, being convicted by their own consciences, went out one by one, beginning at the eldest (63-64).
} 
trayectoria literaria, y reconocida por sus contemporáneos y la posteridad. Pero no cabe duda de que, consciente del impacto del título que consta en la portada, potente iluminador del mensaje pretendido en el tratado, utilizó a Quevedo como instrumento idóneo para su propio contexto político: antídoto certero contra tiranos inspirados por Maquiavelo, estadistas ateos, avezados alumnos de la escuela de Satanás.

En el siglo XVIII, durante ese "momento maquiavélico" en que la reputación del florentino obtiene las más elevadas cotas de reconocimiento en Inglaterra, la pluma de Quevedo, reinterpretada por su traductor, dibuja un "instante antimaquiavélico" insospechado: Christian Politicks, sesgada versión inglesa de la Politica de Dios contra la "sinrazón de estado".

\section{Bibliografía}

Abellán García, J. (2001). Sobre el concepto de república en las décadas finales del siglo XVIII. Revista de Occidente, 247, pp. 107-120.

Alonso Veloso, M. J. (2013). Noticia sobre una traducción al italiano de Doctrina moral de Quevedo. La Perinola, 17, 203-228.

Alonso Veloso, M. J. (2015a). La recepción europea del Marco Bruto de Quevedo: traducciones hasta el siglo XVIII. En F. Gherardi y M. Á. Candelas (eds.), La transmisión de Quevedo (pp. 23-58). Vigo: Academia Editorial del Hispanismo.

Alonso Veloso, M. J. (2015b). Los títulos de Quevedo. La Perinola, 19, pp. 111-148.

Alonso Veloso, M. J. (en prensa), La politique de Dieu, le gouvernement de Jesus Christ et la tirannie de Satan: una traducción desconocida de la obra de Quevedo, en un manuscrito de siglo XVII, Dicenda.

Alonso Veloso, M. J. (2016), Quevedo, antídoto contra los whigs y los tories en la Inglaterra del siglo XVIII, Signa, 25, pp. 339-372.

Althusser, L. (2008). La soledad de Maquiavelo. Marx, Maquiavelo, Spinoza, Lenin. Madrid: Akal, 2008.

Arbesú, D. (2006). La manipulación ideológica de las obras de Quevedo en la Inglaterra del siglo XVII. La Perinola, 10, pp. 317-338.

Arienzo, A. y Borrelli, G. (2009). Anglo American Faces of Machiavelli. Machiavelli e Machiavellismi nella cultura anglo-americana (secoli XVI-XX). Monza: Polimetrica.

Baldwin, G. P. (2010). La traducción de obras de teoría política en Europa a principios de la edad moderna. En P. Burke y R. Po-Chia Hsia (eds.), La traducción cultural en la Europa moderna (pp. 121-152). Madrid: Akal.

Barker, J. W. (1945). Notas sobre la influencia de Quevedo en la literatura inglesa. Boletín de la Biblioteca de Menéndez Pelayo, 21, pp. 429-435.

Barone, L. (2014). La Carta a Luis XIII de Quevedo y la polémica antifrancesa en Italia en el siglo XVII. Pamplona: Eunsa.

Brewer, J. (1976). Party Ideology and Popular Politics at the Accession of Georges III. New York: Cambridge University Press.

Briggs, A. (1994). Historia social de Inglaterra, Guillermo Carrascón Garrido (trad.). Madrid: Alianza Editorial.

Burke, P. (2010). Culturas de traducción en la Europa moderna. En P. Burke y R. Po-Chia Hsia (eds.), La traducción cultural en la Europa moderna (pp. 11-44). Madrid: Akal. 
Cantarino, E. (1996). Tratadistas político-morales de los siglos XVI y XVII (Apuntes sobre el estado actual de la investigación). El Basilisco, 21, pp. 4-7.

Clamurro, W. H. (1991). Language and Ideology in the Prose of Quevedo. Newark, Delaware: Juan de la Cuesta.

Clark, P. (1977). English Provincial Society from the Reformation to the Revolution: Religion, Politics and Society in Kent 1500-1640. Hassocks, Sussex: The Harvester Press.

Crosby, J. O. (ed.) (1966). Francisco de Quevedo, Política de Dios, Gobierno de Christo. Madrid: Castalia.

Díaz Martínez, E. (ed.) (2000). Francisco de Quevedo, Discurso de las privanzas. Pamplona: EUNSA.

Donaldson, P. S. (1988), Machiavelli and Mystery of State. Cambridge: Cambridge University Press.

Dycke, P. van (1904). Reginald Pole and Thomas Cromwell: An Examination of the Apologia ad Carolum Quintum, The American Historical Review, 19, 4, pp. 696-724.

Ehrlicher, H. (2011). Quevedo en Alemania. La Perinola 15, pp. 95-111.

Eminowicz, T. (1984). Sobre una traducción de la Política de Dios, de Francisco de Quevedo, al polaco. Dicenda, 3, 273-277.

Fernández-Guerra y Orbe, A. (ed.) (1946). Francisco de Quevedo, Obras de don Francisco de Quevedo Villegas. BAE 23 y 48, Madrid: M. Rivadeneyra.

Fernández-Santamaría, J. A. (1986). Razón de Estado y política en el pensamiento español del Barroco (1595-1640). Madrid: Centro de Estudios Constitucionales.

Formoso Herrera, M. (1973). Maquiavelo patriota. Revista de Ciencias Sociales, 7, pp. 61-66.

García, E. (2002). Estudio preliminar. Una propuesta de relectura del pensamiento político: J. Pocok y el discurso republicano cívico. En Pocock, J. (2002), El momento maquiavélico. El pensamiento político florentino y la tradición republicana atlántica (pp. 11-73). Madrid: Tecnos.

Garzelli, B. (2011). Traducción y mundos posibles. Los sueños de Quevedo traducidos al italiano. La Perinola, 15, pp. 157-169.

Ghia, W. (1994). Il pensiero politico di Francisco de Quevedo. Pisa: ETS.

Gracián, B. (2000). El Criticón, ed. Santos Alonso. Madrid: Cátedra.

Hazard, P. (1988). La Crisis de la conciencia europea (1680-1715). Madrid: Pegaso.

Hernández Arias, J. R. (1999). Política de Dios y gobierno de Cristo: Quevedo contra Maquiavelo. En Actas de AISO (pp. 700-707).

Iglesias, R. (2010), Cómo ha de ser el privado de Francisco de Quevedo y la tradición española antimaquiavélica de los siglos XVI y XVII. La Perinola, 14, pp. 101-127.

Kenyon, J. P. (1977). Revolution Principles. The Politics of Party, 1689-1720. New York: Cambridge University Press.

Khan, V. (1994). Machiavellian Rhetoric. From the Counter-Reformation to Milton, Princeton (New Jersey), Princeton University Press.

Kwiatkowska Farys, E. (2002). Las traducciones polacas de Quevedo, 1133-1140. Actas de la AISO, VI.

Lida, R. (1968-1969). Sobre la religión política de Quevedo. Anuario de Letras, VII, pp. 201217.

Lida, R. (1981). Prosas de Quevedo. Barcelona: Crítica.

Lira, O. ([1948]). Visión política de Quevedo. Madrid: Seminario de Problemas Hispanoamericanos.

Maltby, J. (1998). Prayer Book and People in Elizabethan and Early Stuart England, Cambridge: Cambridge University Press.

Marañón Ripoll, M. (2005). La razón de Estado, el intelectual y el poder en un texto de Quevedo. Criticón, 93, pp. 39-59.

Martinengo, A. y Símini, D. (2003). La primera traducción italiana del Buscón. En A. Rey (coord.), Estudios sobre el Buscón (pp. 273-294). Pamplona: Eunsa.

Mosse, G. L. (1950). The Struggle for Sovereignty in England, from the Reign of Queen Elizabeth to the Petition of Right. East Lansing: Michigan State College Press. 
Navarro Errasti, M. P. (1987). Quevedo en lengua inglesa. De clásicos y traducciones: versiones inglesas de clásicos españoles (ss. XVI y XVII), 165-187. Barcelona: PPU.

Nider, V. (2011). Nicolò Serpetro, traductor del Marco Bruto de Quevedo. La Perinola 15, 171 190.

Nider, V. (2012). Texto y contexto de dos traducciones olvidadas: la Carta a Antonio de Mendoza de Quevedo y la Instrucción al Exercicio de la muerte de Luisa de Padilla, condesa de Aranda. Il prisma di Proteo: riscritture, ricodificazioni, traduzioni fra Italia e Spagna (sec. XVI-XVII) (pp. 481-504). Trento: Università degli Studi di Trento.

Nider, V. (2013). Una 'consolatio' de Quevedo: la Carta a Antonio de Mendoza. Firenze: Alinea Editrice.

Peltonen, M. (1992). Politics and Science: Francis Bacon and the True Greatness of States. The Historical Journal, 35, pp. 279-305.

Pocock, J. (2002). El momento maquiavélico. El pensamiento político florentino y la tradición republicana atlántica. Madrid: Tecnos.

Procacci, G. (1995). Machiavelli nella cultura europea dell'età moderna. Roma: Editori Laterza.

Questier, M. C. (1996). Conversion, Politics and Religion in England, 1580-1625. Cambridge: Cambridge University Press.

Quevedo, F. de (1655). Política de Dios y gobierno de Cristo, nuestro Señor. Madrid: Pedro Coello.

Quevedo, F. de (1697). Fortune in her Wits, or the Hour of all Men, translated into English by capt. John Stevens. London.

Quevedo, F. de (1715). Divine maxims of Government without Whig or Tory. Or the true character of a King and of a tyrant, of a faithful minister and of a favourite traitor, by D. Francisco de Quevedo Villegas, author of the Visions of Hell, \&c. London: Printed and sold by James Roberts at the Oxford-Armas in Warwick-lane.

Quevedo, F. de (1720). Christian politicks, in opposition to the folly of Matchavellian tyrants, and atheistical statesmen; for the conversion or confusion of those worldly great men, who learn their infamous maxims in the school of Satan. Written in Spanish by Don Francisco de Quevedo Villegas, Knight of the Order of Santiago, Author of the celebrated Visions of Hell, \&c. Now first Translated into English. London: Printed by $J$ Bettenham, and sold by T Bickerton, at the Crown in Pater-noster Row.

Quevedo, F. de (1932): Obras completas. Obras en verso, L. Astrana Marín (ed.). Madrid: Aguilar.

Quevedo, F. de (1946): Epistolario completo, L. Astrana Marín (ed.). Madrid: Instituto Editorial Reus.

Quevedo, F. de (1961). Providencia de Dios, padecida de los que la niegan, y gozada de los que la confiesan. Doctrina estudiada en los gusanos y persecuciones de Job. En F. Buendía (ed.), Obras completas. Obras en prosa (pp. 1541-1617). Madrid: Aguilar.

Quevedo, F. de (1966). Política de Dios, Govierno de Christo, J. O. Crosby (ed.). Madrid: Castalia.

Quevedo, F. de (2003). Discurso de todos los diablos, o infierno emendado. En A. Rey (dir.), Obras completas en prosa, Obras satírico-morales, I, 2 (pp. 469-560). Madrid: Castalia.

Quevedo, F. de (2012). Discurso de las privanzas, E. M. Díaz Martínez (ed.). En A. Rey (dir.), Obras completas en prosa. Tratados politicos, V (pp. 87-158). Madrid: Castalia.

Quevedo, F. de (2012). Política de Dios, E. Ma . Díaz Martínez (ed. parte primera) y R. Cacho Casal (ed. parte segunda). En A. Rey (dir.), Obras completas en prosa. Tratados politicos, V (pp. 159-639). Madrid: Castalia.

Quevedo, F. de (2012). Primera parte de la vida de Marco Bruto, Alonso Veloso, M. J. (ed.). En A. Rey (dir.), Obras completas en prosa, Tratados políticos, V (pp. 641-984). Barcelona: Castalia.

Raab, F. (1964). The English Face of Machiavelli: a changing interpretation 1500-1700, Routledge and Kegan Paul, Londres-Toronto. 
Rey, A. (2012). Introducción. En A. Rey (dir.), Obras completas en prosa. Tratados políticos, V. Madrid: Castalia, pp. 9-83.

Rey, A. (2013). Quevedo ante Maquiavelo. En M. J. Alonso Veloso y A. Rey (coord.), Italia en la obra de Quevedo (pp. 17-33). Santiago de Compostela: Universidad.

Rey, A. (2015). Introducción. En A. Rey (dir.), Obras completas en prosa. Memoriales, V. Barcelona: Castalia, pp. IX-XLVIII.

Rey, A. (2015). The Last Days of Humanism. A Reappraisal of Quevedo's Thought. Cambridge: Modern Humanities Research Association.

Ríos Espinosa, M. C. (2011). Maquiavelo en el pensamiento político de Inglaterra en el siglo XVIII y en el pensamiento social de Bernard Mandeville, Nueva época, 65, pp. 137167.

Roig Miranda, M. (2011). La recepción de Quevedo en Francia. La Perinola 15, pp. 235-261.

Roig Miranda, M. (1997). Las traducciones francesas de los Sueños de Quevedo en el siglo XVII y hasta 1812 (Nota bibliográfica). En Quevedo a nueva luz: escritura y política (pp. 165-212). Málaga: Universidad.

Roig Miranda, M. (2000). Edición y anotación de Les Visions del Sieur de La Geneste. La Perinola, 4, pp. 367-378.

Rosman, D. (1996). From Catholic to Protestant. Religion and the People in Tudor England. London: University College London (UCL).

Scott, E. J. L. (1904). Index to the Sloane Manuscripts in the British Museum. London: M. A. D. Litt.

Scott, J. (2000). England's Troubles. Seventeenth-century English Political Instability in European Context. Cambridge: Cambridge University Press.

Skinner, Q. (1998). Liberty Before Liberalism. Cambridge: Cambridge University Press.

Varela Suanzes-Carpegna, J. (2000). El constitucionalismo británico entre dos revoluciones: 1688-1789. Fundamentos: Cuadernos monográficos de teoría del estado, derecho público e historia constitucional, 2, pp. 25-96.

Várnagy, T. (2000). El pensamiento político de John Locke y el surgimiento del liberalismo, La filosofia politica moderna. De Hobbes a Marx, Atilio A. Boron (comp.). Buenos Aires: CLACSO.

Weidhorn, M. (2012). Dante's Machiavellian Moment, Papers on Language and Literature, 48, 2, pp. 219-222.

Williams, R. H. (1936). A manuscript document on the translation from Spanish by captain John Stevens. Revue de Littérature Comparée, pp. 144-166.

Woodward, E. L. (1993). Historia de Inglaterra, Madrid, Alianza Editorial, 1993. 